\title{
COVID-19 and the need to prioritize health equity and social determinants of health
}

\author{
Amirhossein Takian ${ }^{1,2,3}$ (1) $\cdot$ Mohammad Mehdi Kiani $^{2,3}$ (]) $\cdot$ Khatere Khanjankhani $^{2,3}$ (])
}

Received: 21 April 2020 / Revised: 21 April 2020 / Accepted: 23 May 2020 / Published online: 28 May 2020

(C) Swiss School of Public Health (SSPH+) 2020

On March 11, 2020, the World Health Organization (WHO) declared the novel coronavirus disease (COVID19) a global pandemic. With over five million infected people and more than 343,000 casualties across 213 countries (World Health Organization 2020b) so far, the crisis has become the most devastating challenge in recent history (Raoofi et al. 2020). Although COVID-19 is a viral disease, a variety of non-biological factors, particularly health inequalities and the social determinants of health $(\mathrm{SDH})$, can affect its prevalence and consequences within communities.

Health equity and addressing SDH are the cornerstone value of any health system (The Lancet 2020). SDH are the non-medical factors that influence health outcomes. Where individuals live, the level of education, work conditions, career, age, along with socioeconomic status and race, all have a tremendous influence on their health status (World Health Organization). The social gradient in the proportion of life spent in ill health is significant, "with those in poorer areas spending more of their shorter lives in ill health" (Marmot 2020). Even in countries like England with a world-known equitable national health system (Mossialos et al. 2017), inequalities in life expectancy have

Amirhossein Takian

takian@tums.ac.ir

Mohammad Mehdi Kiani

mehdi.kiyan92@gmail.com

Khatere Khanjankhani

kh.khanjankhani@gmail.com

1 Department of Global Health and Public Policy, School of Public Health, Tehran University of Medical Sciences (TUMS), Tehran, Iran

2 Health Equity Research Center (HERC), Tehran University of Medical Sciences (TUMS), Tehran, Iran

3 Department of Health Management and Economics, School of Public Health, Tehran University of Medical Sciences (TUMS), Tehran, Iran widened and life expectancy fell in the most deprived communities, while the amount of time spent in poor health has increased in the last decade (Marmot 2020; The Lancet 2020). As a result, "the country has been moving in the wrong direction", and "lives for people toward the bottom of the social hierarchy have been made more difficult." (The Lancet 2020).

COVID-19 pandemic has involved people from various socioeconomic groups, poor and rich, in low, middle and high-income countries alike. Although the burden of pandemic is becoming significantly higher in some of the richest nations, more people in lower socioeconomic quantiles are facing devastating consequences compared to their socioeconomically better off counterparts (Buchanan et al. 2020). Previous studies have confirmed the relationship between mortality and socioeconomic class (World Health Organization 2020a). At least the risk of preventable death is three times higher for people living in the most compared the least deprived areas (Marmot 2020). Even for those well above the poverty line, earning less is associated with higher rates of chronic health conditions, which might also make the novel coronavirus deadlier among them (Zhi 2020). Worse still in countries like Iran the double burden of current epidemic and political sanctions (Raoofi et al. 2020) may widen the existing gap between various socioeconomic groups, while the poor might be more likely to suffer or die during the outbreak.

The rich, however, have the potential to make a living, and through their social networks, to be more up-to-date about the latest information and recommendations on the COVID-19 pandemic and ways to mitigate its risks. A recent analysis of smartphone location data in cities across the USA by The New York Times shows many lowerincome workers (the bottom 10 percent of income) continue to move around during quarantine, while those who make more money are staying home and limiting their exposure (Buchanan et al. 2020). The data offer real-time evidence of a divide laid bare by the pandemic — one in 


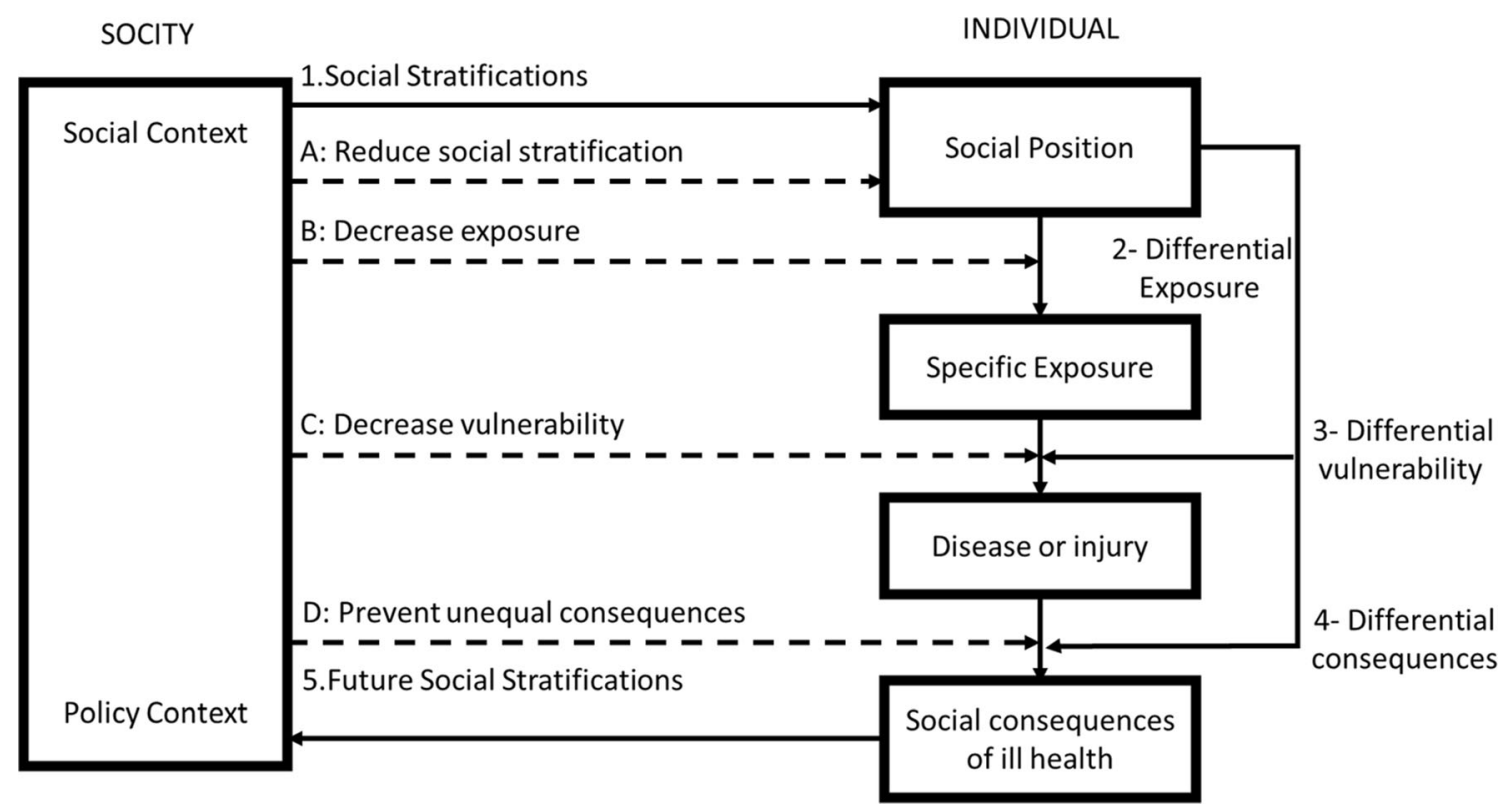

Fig. 1 The relationship between social context and specific exposure results

which wealthier people not only have more job security and benefits, but also may be better able to avoid becoming sick.

Addressing SDH appropriately is fundamental for improving health and reducing longstanding inequalities in health and healthcare. With no definitive cure available and a vaccine being at least 1 year away, the current COVID-19 crisis has imposed yet another strong battle to health equity and bridging the gap to access needed healthcare between the rich and poor, as people in higher socioeconomic quantiles are better able to combat and cope with it. Figure 1 shows the relationship between social context and specific exposure (such as COVID-19) results (Diderichsen et al. 2012).

As COVID-19 pandemic is directing the entire world toward a once in a lifetime economic recession, human societies cannot afford inaction on health inequalities. Health is a political choice. COVID-19 is not the first deadly pandemic with millions of people affected worldwide, and it is certainly not the last one to happen. To rebuild the world where everyone benefits from the human right to health, all nations need to consider the ongoing pandemic a wake-up call to expedite global efforts to address health inequalities and SDH. SDH are causes of causes toward health equity and attain social justice. Viruses do not discriminate, nor should health systems.

Funding We used no fund and no consent was required.

\section{Compliance with ethical standards}

Conflict of interest The authors declare that they have no conflict of interest.

\section{References}

Buchanan L, Patel JK, Rosenthal BM, Singhv A (2020) A month of coronavirus in New York city: See the hardest-hit areas. https:// www.nytimes.com/interactive/2020/04/01/nyregion/nyc-corona virus-cases-map.html. Accessed 17 Apr 2020

Diderichsen F, Andersen I, Manuel C, Andersen AM, Bach E, Baadsgaard $\mathrm{M}$ et al (2012) Health inequality-determinants and policies. Scand J Public Health 40(8 Suppl):12-105. https://doi. org/10.1177/1403494812457734

Marmot M (2020) Health equity in England: the Marmot review 10 years on. BMJ 368:m693. https://doi.org/10.1136/bmj.m693

Mossialos E, Djordjevic A, Osborn R, Sarnak D (2017) International profiles of health care systems. The Search Results Web result with site links Commonwealth Fund. https://www.common wealthfund.org/publications/fund-reports/2017/may/interna tional-profiles-healthcare-systems. Accessed 26 May 2020

Raoofi A, Takian A, AkbariSari A, Olyaeemanesh A, Haghighi H, Aarabi M (2020) COVID-19 pandemic and comparative health policy learning in Iran. Arch Iran Med March 23(4):220-234. https://doi.org/10.34172/aim.2020.02

TheLancet (2020) Taking urgent action on health inequities. Lancet (London, England) 395(10225):659

WorldHealthOrganization About social determinants of health. https://www.who.int/social_determinants/sdh_definition/en/. Accessed 8 Apr 2020

WorldHealthOrganization (2020a) Basic protective measures against the new coronavirus. https://www.who.int/emergencies/diseases/ novel-coronavirus-2019/advice-for-public. Accessed 26 May 2020 
WorldHealthOrganization (2020b) Coronavirus (COVID-19). https:// who.sprinklr.com/. Accessed 17 Apr 2020

Zhi ZLXBXZ (2020) The epidemiological characteristics of an outbreak of 2019 novel coronavirus diseases (COVID-19) China 2020. Chin Center Dis Control Prev 2(8):113-122. https:// doi.org/10.3760/cma.j.issn.0254-6450.2020.02.003
Publisher's Note Springer Nature remains neutral with regard to jurisdictional claims in published maps and institutional affiliations. 